\section{ECONOMICS}

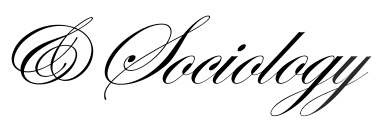

Braw, Y., Cohen, E., Brender-Ilan, Y., Sohlberg, I. (2018). A Call for Establishing a Public Policy for Mitigating the Effects of Dementia on Modern Workplaces. Economics and Sociology, 11(1), 172-187. doi:10.14254/2071-789X.2018/11-1/11

\title{
A CALL FOR ESTABLISHING A PUBLIC POLICY FOR MITIGATING THE EFFECTS OF DEMENTIA ON MODERN WORKPLACES
}

\author{
Yoram Braw, \\ Ariel University, \\ Ariel, Israel, \\ E-mail:yoramb@ariel.ac.il \\ Erez Cohen, \\ Ariel University, \\ Ariel, Israel, \\ E-mail:erez@ariel.ac.il
}

Yael Brender-Ilan,

Ariel University,

Ariel, Israel,

E-mail:yaelb@ariel.ac.il

\author{
Idit Sohlberg, \\ Ariel University, \\ Ariel, Israel, \\ E-mail: aditso@ariel.ac.il
}

Received: September, 2017

1st Revision: December, 2017

Accepted: January, 2018

DOI: $10.14254 / 2071-$

789X.2018/11-1/11

JEL Classification: I18, J08, J18

\begin{abstract}
The rise in life expectancy leads to a steady increase in the number employees with neurodegenerative disorders (i.e., dementia) and progressively declining vocational functioning. In the current paper, we describe these changes at the labor market and the challenges they entail. We point towards the key issues that should be taken into consideration when establishing policies for the aging labor market. These include implementing procedures for the early diagnosis of employees with dementias, educating employers regarding dementia and assisting employees already diagnosed with this and other disorders. These solutions will benefit both employees and the workplace overall, as well as decrease misconceptions about aging and dementia. These solutions are thereby to transform the work environment to be more responsive to the needs of employees with declining vocational functioning.
\end{abstract}

Keywords: Longevity; Dementia; Employment; Work; Labor; Public Policy.

\section{Introduction}

Steady increase in life expectancy in developed countries has resulted in a corresponding increase in the proportion of elderly employees at the labor market. Consequences of these changes have been acknowledged and their implications are receiving increasing scholarly attention. For example, effect on leisure activity (Karev \& Doron, 2017), impact on health (Staudinger et al., 2016), workers' productivity (Van Dalen et al., 2010) and age discrimination in the workplace (Truxillo et al., 2017) have all been addressed with regard to population aging. There has been a corresponding growth of interest in neurodegenerative 
disorders (i.e., dementia) as the age composition of population also changes (Mehta \& Yeo, 2017; Rossor et al., 2016).

The expected steady upsurge in elderly employees with dementia, however, did not receive adequate attention up-to-date (see: 2. Methodological approach). This is unfortunate as it is expected to be a key factor in shaping the future labor market. The current qualitative review aims to: (a) Briefly review of the ongoing rise in life expectancy and its impact on the labor market, issues that were addressed in earlier publications (e.g., Harper, 2014). (b) Delineate the challenges that these changes entail. (c) Encourage informed decision making by acquainting policymakers with the knowledge that was gained over the years in the field of geriatric clinical neuropsychology (Rycroft \& Giovannetti, 2017).

\section{Literature review}

\subsection{Rise in life expectancy and its impact on the labor market}

Life expectancy at birth in developed countries has increased by about 30 years in the last century (Christensen et al., 2009). As evident in Graph 1, life expectancy at birth was 48.35 years in 1900. In contrast, those born in 2014 could expect to live, on average, 81.89 years.Correspondingly, conditional life expectancy in old age is also rising. As shown in Graph 1. Labor force participation rate, 65 or older, percent in same age group (i.e., number of employed people of a given age as a percentage of the total number of people in that same age group), OECD countries, 2000-2015.

Labor force participation rate, 65 or older, percent in same age group (i.e., number of employed people of a given age as a percentage of the total number of people in that same age group), OECD countries, 2000-2015, 65 year-olds were expected to live an additional 11.85 years at the beginning of the $20^{\text {th }}$ century and are now expected to live for another 20.34 years. This unprecedented and rapid aging of the population is correlated with major technological and medical advances. For example, the first half of the $20^{\text {th }}$ century witnessed a sharp decline in infant mortality rates while a decrease in tobacco use and cardiovascular disease mortality were evident in more recent decades (Mathers et al., 2015). 


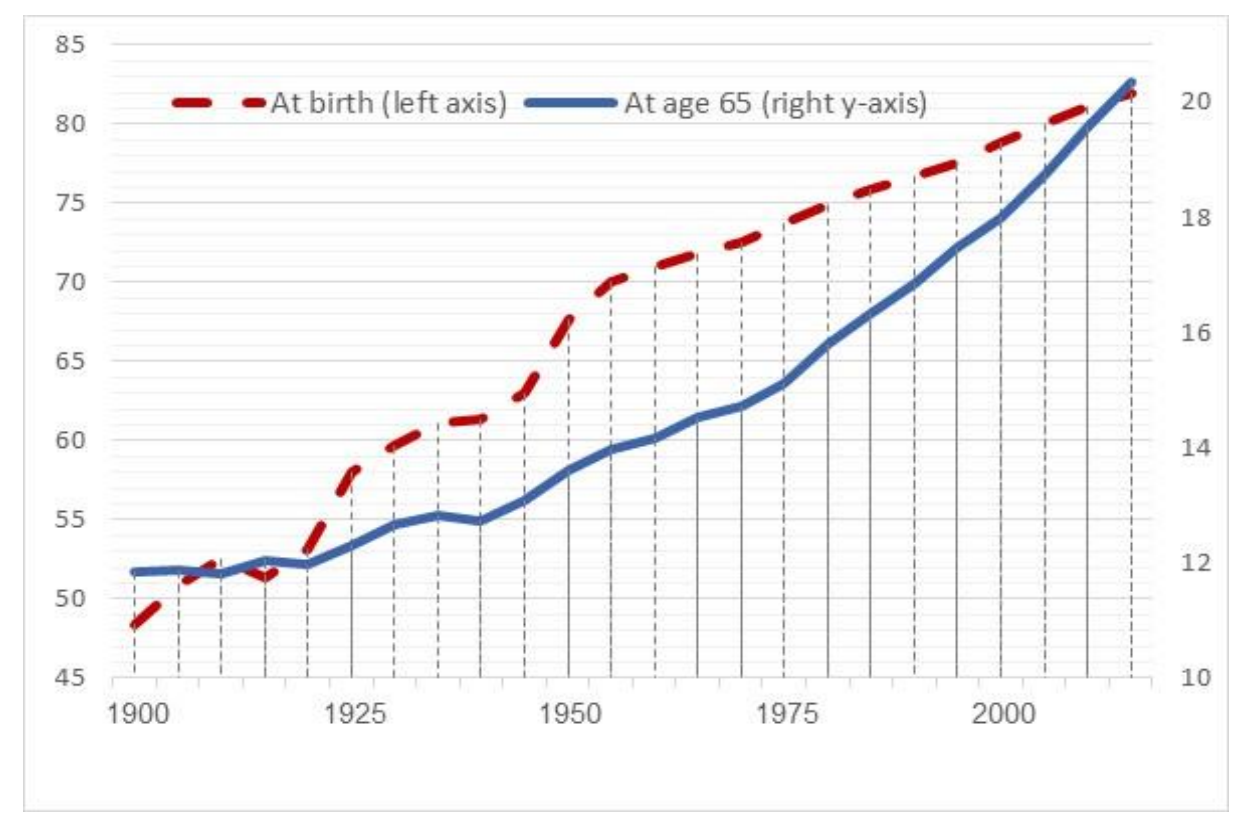

Graph 1. Life expectancy at birth, and conditional life expectancy at age 65, average of OECD countries ${ }^{1}, 1900-2014$

Source: The Human Mortality Database (HMD).

The aging of the population is expected to continue and by 2050 two billion people will be aged 60 or older, accounting for $21 \%$ of the world's population (Harper, 2014). The elderly will consequently comprise an increasingly larger segment of the population, a change that will be particularly notable for those older than 80; their number, worldwide, will rise from 69 million to 379 million by 2050 , at which point they will comprise nearly $10 \%$ of the population of developed countries (Harper, 2014). This will have a profound impact on the labor market, one that is already felt at present. More specifically, the aging of the population necessitates larger financial reserves and more far-sighted planning by individuals before retirement. It also threatens the financial stability of pension funds, leading state and local governments to allocate an increasing proportion of their budgets to retirement benefits (Kiewiet \& McCubbins, 2014). These measures, however, are insufficient and the system in its current form has been deemed unsustainable (Baruch et al., 2014). Consequently, sociopolitical pressures are mounting to raise the age of retirement and even abolish fixed-age retirement altogether (Baruch et al., 2014). These have a synergic effect with other public policy and societal changes, including: (a) Legislation and court decisions that make layoff procedures more complicated and, consequently, decrease the retirement of elderly employees (e.g., prelayoff due process hearing requirements, age discrimination legislation, etc.) (b) Changes in the perception of employment on the individual level (e.g., recognizing the positive effect of work on preservation of cognitive functioning during aging; Phillips, 2017). (c) Changes in the conceptualization of retirement on the societal level. More specifically, mandatory retirement is increasingly perceived as infringing on basic human rights (e.g., freedom of occupation) and a form of ageism.

All of the above-mentioned factors fuel a steady rise in the proportion of elderly employees in the labor market. As can be evident in Graph 2, the labor force participation rate

\footnotetext{
${ }^{1}$ Austria, Denmark, France, Germany, Iceland, Israel, Japan, Italy, Canada, Norway, Netherlands, Spain, Sweden, Switzerland, UK, and the US. Source: The Human Mortality Database (HMD).
} 
in OECD countries of those under 65 was relatively stable between 2000 and 2015. In contrast, the participation rate of persons over 65 has steadily increased during this period. For example, the labor force participation rate in the same age group grew from $11.01 \%$ in 2000 to $14.20 \%$ in 2015 in OECD countries (see Graph 2).

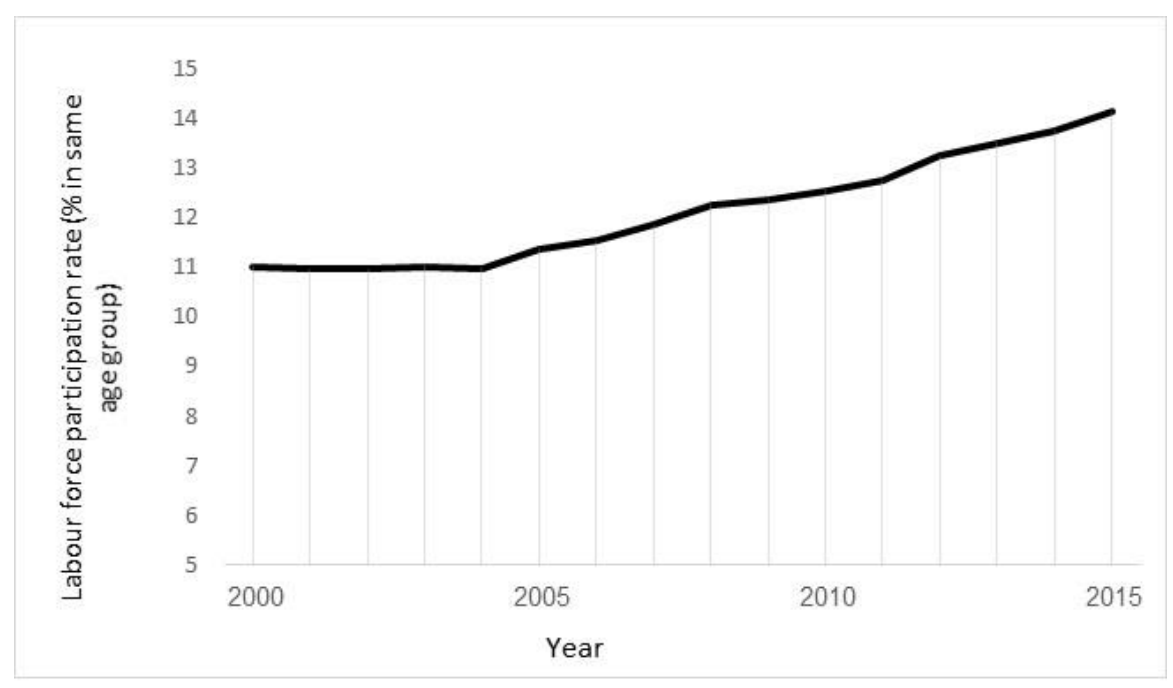

Graph 2. Labor force participation rate, 65 or older, percent in same age group (i.e., number of employed people of a given age as a percentage of the total number of people in that same age group), OECD countries, 2000-2015

Source: Labor Market Statistics, OECD Database.

Analysis of change in labor force participation rates over the years is also illuminating. As is evident in Graph 3 between 2000 and 2015 the overall labor force participation rate declined by $2.51 \%$ (as described earlier, for example; Fujita, 2014; Hipple, 2016). This sharply contrasts with the substantial increase in participation rate (i.e., 59.49\%) that was evident in those aged 65 or older. Moreover, the increase is associated with age; between 2000 and 2016 there was a larger increase in participation rate among those aged 75 or older as compared to those 65 or older (66.7\% and 59.3\%, respectively; see Appendix). The increase was also more notable among females during this period; there was a $75.9 \%$ increase among females aged 65 to 74 years as compared to an increase of $45.3 \%$ among males. See Appendix. 


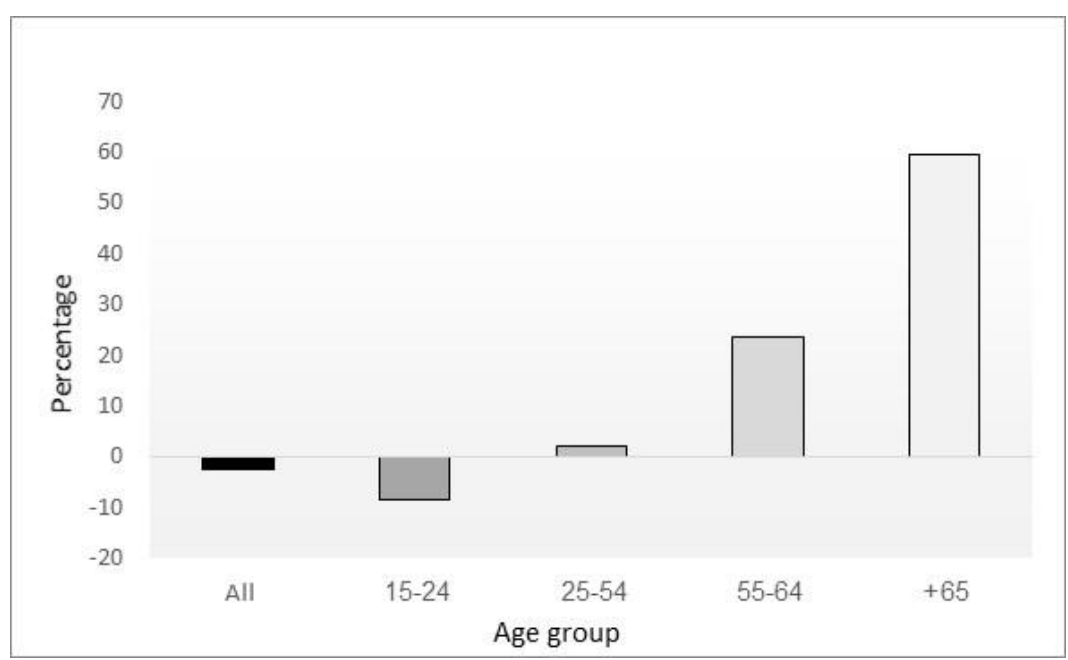

Graph 3. Labor force participation, rate of change stratified by age, OECD countries, 2000 to 2016 Source: OECD database.

Elderly dependency ratios (EDRs) are defined as the ratio of persons aged 65 or older from the working-age population (i.e., under 65). Corresponding to the earlier presented findings, a rapid shift toward increased EDRs was evident in most developed countries over the last decades. For example, EDRs in OECD countries rose from $17.55 \%$ in 1990 to $25.45 \%$ in 2016 (see Graph 4).

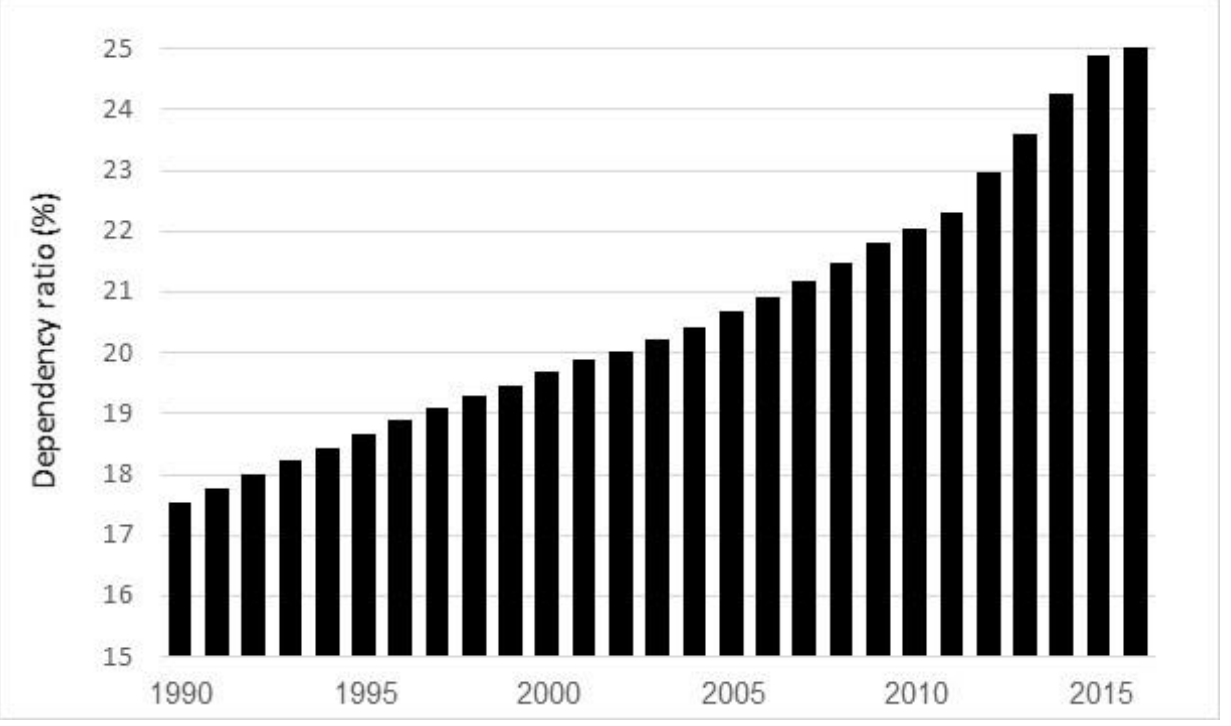

Graph 4. Dependency ratio (\%) of the elderly (ages 65+ / ages 20-64), OECD countries, 19902016

Source: Labor market statistics, OECD Database.

To conclude, the proportion of elderly employees in the labor market is steadily rising, necessitating changes on both the individual and societal level (e.g., reorganization of retirement arrangements in order to sustain an adequate quality of living in old age; McGrattan 
\& Prescott, 2017). Beyond these obvious challenges, however, the aging workforce will also face a more insidious challenge, as will be detailed in the following sections.

\subsection{Neuropsychological consequences of the changes in longevity}

Aging is accompanied by a natural decline in several cognitive abilities (Verhaeghen, 2013). This age-related cognitive decline (ARCD; Smith \& Rush, 2006) mainly affects fluid intelligence, the ability to use abstract relational reasoning in order to solve novel problems (Chuderski, 2013). It also impacts working memory (i.e., the ability to store information for short periods of time and manipulate it) and other processes in which time constraints play a crucial role. Although the exact mechanisms underlying these changes are still debated (e.g., Bugg et al., 2006), they are correlated with structural and functional changes in the brain (Murman, 2015; Wyss-Coray, 2016). Healthy aging, however, is usually not associated with decreased productivity. This mainly stems from the ability of elderly employees to adapt themselves to their changing abilities while continuing to accumulate professional experience and knowledge (Li et al., 2015). Correspondingly, Burtless (2013) concluded that there is little evidence of lowered productivity of an aging workforce. In fact, the author suggested that elderly employees may be more productive than average workers who are younger (Burtless, 2013).

Some individuals, however, experience a decline in cognitive functioning that goes beyond natural age-associated changes. Dementia is a clinical syndrome caused by a progressive degeneration of the brain (Hardiman et al., 2016). It is characterized by a decline in cognitive (e.g., memory, language, and problem-solving), emotional, and behavioral functioning. These are manifested in declining daily functioning and dwindling capacity for independent living (Hugo \& Ganguli, 2014; Welsh-Bohmer \& Warren, 2006). Differences in the brain regions in which the degeneration commences determine the initial symptoms of the disease and thereby the sub-category of dementia the patients will be diagnosed with. For example, Alzheimer's disease is the most common type of dementia, accounting for approximately $70 \%$ of dementia cases (Reitz \& Mayeux, 2014). It is characterized by a decline in memory and learning capacity as a result of damage to the hippocampus and related brain structures (Welsh-Bohmer \& Warren, 2006). These symptoms contrast with those of other dementias in which initial symptoms may, for example, be manifested in behavioral-emotional disturbances (e.g., frontotemporal dementia, FTD; see elaboration in the next section). As the disease progresses and additional brain regions are affected, the different dementias become increasingly similar to one another as the patients progressively lose their ability to perform even basic daily functions.

The decline in functioning that characterizes dementia may begin years before a formal diagnosis is given (Brown, Devanand, Liu, \& Caccappolo, 2011). This is clearly evident in longitudinal studies (e.g., a study with an impressive follow-up period of 18 years; Rajan et al., 2015). The decline in this stage of the disease is primarily manifested in instrumental activities of daily living (iADLs). These include the ability to assemble tax records and other important documents, pay attention and comprehend information, remember appointments, and drive safely (see also p. 620 in Brown et al., 2011). For example, Ronald Reagan was diagnosed with Alzheimer's disease after the end of his second term in office. The decline in his functioning may, however, have already begun during his presidency; Berisha, Wang, LaCross, and Liss (2015) analyzed Reagan's transcripts and found a reduction in the number of unique words and an increase in conversational fillers and non-specific nouns over time. This vivid example illustrates the insidious pathological process of dementia and its emergence years before a formal diagnosis is even contemplated. 


\subsection{Dementia and the future labor market}

Aging is strongly associated with an increased risk of developing dementia. For example, the prevalence of Alzheimer's disease increases exponentially with age, reaching almost 50\% among those 85 or older (Castellani et al., 2010). The increased life expectancy has, therefore, a direct impact on the number of dementia patients. Epidemiological data makes this fact painfully clear; an estimated 35.6 million people lived with dementia worldwide in 2010 and their number is expected to almost double every 20 years, reaching 65.7 million in 2030 and 115.4 million in 2050 (Prince et al., 2013). Since elderly employees constitute an increasing proportion of the workforce, the number of employees with dementia is expected to steadily increase with time. This growth will have numerous negative consequences in both the individual and organizational levels and will radically reshape the workplace. For example, employees with Alzheimer's disease may forget to perform tasks, maintain appointments, and will generally perform their work inefficiently. Other impairments may have even more subtle effects on employees' vocational functioning. For instance, emotional-behavioral disturbances (e.g., irritability and difficulty in comprehending social cues) may strain interactions with coworkers/supervisors and thereby affect work atmosphere and lead to decreased productivity.

Studies of occupational competence of older workers with dementia give a glimpse to the likely effects of the disease on the workplace. Evans (2016) found that the emergence of dementia took the form of a slow transition that was not noticed at first by co-workers. Subtle changes included forgetfulness, disorganization, errors, and sluggishness. Only later, as the person's functioning continued to deteriorate, did co-workers begin to note these changes. This last point stresses the fact that employees' functional decline may go unrecognized, at least in the initial stages of the disease. Moreover, the functional decline may be interpreted erroneously even after it becomes noticeable. For example, Evans (2016) notes that, as their functioning progressively declined, these employees experienced difficulties with co-workers and supervisors and were perceived as workers of poor quality. This suggests that both supervisors and co-workers may overlook the possibility that dementia as the source of an employee's functional decline. Moreover, they may still fail to establish an appropriate work environment for the employee even after becoming aware of his/hers diagnosis. This is not particularly surprising since the general public has common misconceptions regarding dementia and only a fair to moderate knowledge of the disease (Cahill et al., 2015). Further complicating matters is the fact that certain types of dementias are not manifested in relatively easily identifiable changes in cognitive abilities. For example, frontotemporal dementia (FTD) typically develops in the sixth decade of life (Onyike \& Diehl-Schmid, 2013). The clinical symptomatology of its behavioral variant is dominated by gradual changes in social behavior and personality (Jones \& Neary, 2016). These changes (e.g., poor decision-making, impulsivity, socially inappropriate behavior, and lack of empathy) may be accompanied by relatively intact cognition, at least in the initial stages of the disease. Thus, identification of this variant of FTD may be particularly challenging and the decline in the employee's functioning may continue for a lengthy period before the existence of dementia is suspected. It can be argued that the employee should notify the employer of changes in his/her medical condition and vocational functioning. However, such a belief is somewhat naive. Moreover, it disregards the fact that a sizable proportion of dementia patients have decreased awareness of their impairments. Impaired awareness (also known as lack of insight or anosognosia) is a key symptom of dementia; patients may outright deny being ill or otherwise minimize the impact of the impairments on their functioning (Lehrner et al., 2015). Thus, the neuropathology of dementia can make it difficult to self-identify impairments and, consequently, reliably report them to employers and co-workers. In fact, seeking medical help may only occur after the urgings of 
family members or other concerned individuals. Taken together, a growing segment of the workforce is likely to be afflicted by vocational impairments of which they- and those around them- may only be partially aware, if at all.

As noted earlier, increased life expectancy and societal changes (e.g., legislation and court decisions) will have a major impact on the labor market. A growing segment of the workforce will consist of employees with dementia and declining vocational functioning. Moreover, vocational decline may go unnoticed- at least in the initial stages of the disease- due to impaired self-awareness the employees, coupled with general lack of public knowledge and misconceptions regarding dementia. Consequently, timely diagnosis of the disease and workplace adjustments (reduction in work responsibilities, retirement etc.) may be delayed. The workplace adjustments may also be adopted inefficiently or, worse, haphazardly as a response to a crisis. These will have a negative effect on both the employee and the workplace.

\section{Methodological approach}

As the first stage of the qualitative review, we assessed the rate of scientific publications focusing on the effect of dementia on the labor market (e.g., employees vocational functioning, policies pertaining to employees with dementia etc.) For this aim, we conducted a nonexhaustive literature search in the electronic databases Scholar, PubMed, and Web of Science in the period between 1906 (first publication by Dr. Alzheimer; Hippius \& Neundörfer, 2003) and November 2017. The search was conducted using the keywords DEMENTIA or NEURODEGENERATIVE DISORDER/S and [WORK* or LABOR/LABOR or VOCATIONAL]. Studies were selected if they included in their title or abstract one of these keywords. The initial literature review suggested that prior to the year 2000, scant attention was given to the subject of dementia in the workplace, though some publications noted the possible effects on care-givers of dementia patients. Noted exceptions were a study that assessed effectiveness of an intervention aimed at improving occupational performance of dementia patients (Josephsson et al., 1995) and a study which addressed general issues pertaining to the aging in the workplace (though dementia was not the focus of the study; McDaniel \& Brenda, 1997). There has been a steady increase in publications since then, likely due to the aging of the population and an increased awareness of the functional impairments that may precede the diagnosis of dementia. With regard to the later development, defining mild cognitive impairment (MCI; Petersen et al., 1999), in an attempt to define pre-dementia conditions, has greatly encouraged such publications. These publications focused initially on young-onset patients (Ohman et al., 2001) and work related factors as a risk factor for the development of dementia (Seidler et al., 2004). These, however, were broadened later to include the effects of dementia on vocational capacity, the early signs of dementia in the workplace, etc. (i.e., broader concerns that the current review focuses upon).

After assessing the longitudinal trends in scientific publications and ascertaining sufficient data to achieve adequate understanding regarding the effects of dementia of the labor market (see; 3.1. Initial litrauture review), we performed the main litrauture review. This review focused on the following topics: (a) Changes in life expectancy and, consequently, the age composition of employees in the labor market. (b) Natural and pathological changes in neuropsychological functioning at old age. (c) Predicted changes in the labour market as a result of the integrative effects of the two earlier topics. Because of the modest number of publications identified in our initial literature review, a qualitative analysis of the literature - rather than quantitative methods (e.g., meta-analytic techniques) - appeared most appropriate. We based the review on the publications found in the initial literature review, as well as a non-exhaustive literature search in the electronic databases Scholar, PubMed, and Web of Science in the period 
between 1990 and November 2017. The search was conducted using the keywords that were noted earlier, as well as keywords that were relevant for each of the topics (e.g., OLD AGE, GERIATR*, ELDER*, LIFE EXPECTANCY, LONGEVITY, ELDERLY DEPENDENCY RATIOS, COGNITI*, ALZHEIMER* etc.). The findings of this qualitative review were summarized and served as the basis for policy recommendations (see next section). This section was based on the authors' prior acquaintance with the topics. Additional literature review was used, when needed, to enhance this prior knowledge and, consequently, the quality of the suggested recommendations.

\section{Discussion and policy recommendations}

Establishing a general retirement policy that responds to the global rise in life expectancy is imperative. Its formulation will necessitate negotiating diverse public and private sector interests. It will also mandate the balancing of intricate economic, legal and ethical dilemmas that go beyond the need to maintain the stability of pension funds. This presents $a$ valuable opportunity to raise awareness regarding the expected effects of dementia on the labor market and to establish coherent and humane policies to deal with these looming challenges. The labor market has adapted to the impact of rapid neuropathological processes that employees sustain at a relatively young age (e.g., traumatic brain injury; Brazinova et al., 2015). In contrast, dementia mainly affects older persons and, therefore, is relatively novel to institutions and policymakers in the labor market. Since the impact of dementia on the labor market is expected to be substantial, careful and thoughtful planning are needed. Following is a list of pressing issues, accompanied by relevant policy recommendations:

\subsection{Early diagnosis of employees with dementias}

Early diagnosis of dementia is vital in light of ongoing efforts to develop more effective treatments for the disease (Laver et al., 2016). Most individuals with cognitive impairmentsincluding dementia- prefer to be informed about their diagnosis as soon as possible, so that they can plan for the future and safeguard their autonomy as much as possible (Pinner \& Bouman, 2003; van den Dungen et al., 2014). Early diagnosis of dementia, however, is challenging due to an overlap between natural age-associated cognitive decline and the effects of dementia (Braw et al., 2012). Moreover, reliance on employee, co-workers, and/or supervisor to identify the decline in functioning and to conceptualize it as a neuropathological process may prove difficult (due to lack of awareness, incomplete knowledge, misconceptions of dementia, etc.) Periodic competency testing of elderly employees may enable early diagnosis of dementia. This, however, will necessitate addressing practical challenges and ethical dilemmas. First, laboratory tests can be used, at present, only as supporting evidence for the diagnosis of dementia. Trained clinicians will, therefore, be required for the evaluation of employees. Trained neurologists, psychiatrists, and clinical neuropsychologists are ideally suited for this purpose, but their services are costly. Cox and Pardasani (2013) suggest that dementia symptoms may be assessed by human resources professionals. However, as the authors note, they do not have any training in mental health or in performing cognitive assessments. They may, therefore, be ill-suited to handle this challenging task. Second, mandatory evaluations of a large segment of the population raise ethical dilemmas regarding employee privacy and autonomy, employer rights to terminate employment based solely on medical diagnosis (i.e., before any significant decline in functioning is evident), etc. (Strech et al., 2013). Employees may oppose a policy of mandatory medical examinations that threatens to lead to work 
termination. They may note in their objections that their employment has additional positive effects, beyond providing financial security. It can, for example, enhance quality of life and satisfaction (van der Heide et al., 2013; van der Noordt et al., 2014) and decrease tension among family members (common in families of dementia patients; Adelman et al., 2014). Employers, in contrast, may call for an even more flexible retirement policy, one that will allow work termination based on additional organizational considerations besides the employee's performance on the dementia evaluation. Overall, the impact of implementing such policies will have to be thoroughly evaluated and alternative solutions entertained. Lessons learned from the emerging field of neuroethics can be of value in this regard (Figueroa, 2016).

\subsection{Establishing psychoeducational programs focused on dementia}

Lack of knowledge and misconceptions regarding dementia are common (Cahill et al., 2015). These include, among others, the erroneous belief that dementia is a normal part of aging and the uncertainty about the point at which normal age-related cognitive decline becomes severe enough to indicate dementia (Cahill et al., 2015) ${ }^{2}$. The knowledge that an employee is diagnosed with dementia, therefore, does not guarantee that it will be utilized in a manner that serves the interests of all involved parties ${ }^{3}$. Psychoeducational programs offer to- at least partially- remedy this state of affairs and should, therefore, be key components of any policy that targets the aging workforce. These programs can enhance the knowledge of policymakers and employers, decrease misconceptions (e.g., those regarding the productivity of older workers; Loretto \& White, 2006; Van Dalen et al., 2010) and combat ageism. The practical gains of such programs include earlier diagnoses of dementia as well as accommodations for employees already diagnosed with the disease. They can also contribute to increased overall efficiency; elderly employees will be recruited based on their merit (rather than ingrained biases) and fewer employees will be dismissed while their vocational functioning is relatively intact. Finally, the incentive to invest in employee training and development will increase as employment is re-conceptualized in longer time frames.

Psychoeducational programs can be constructed based on prior experience with similar programs in the field of psychogeriatrics (e.g., Jensen et al., 2015). Of note is a recent review by Surr et al. (2017) that stipulates common features of efficacious educational programs for those working with dementia patients (i.e., health and social care workforce). With regard to the labor market, a pilot study by Cox and Pardasani (2013) suggests that human resources professionals were very interested in additional training and information on dementia and how to discuss it with employees. Furthermore, the authors noted that social workers can play important roles in instituting policies and programs that meet the needs of both employees with dementia and their caregivers (Cox \& Pardasani, 2013). These constitute both a target of psychoeducational programs and ambassadors for spreading knowledge and promoting better integration of elderly employees in the workforce.

\subsection{Aiding employees diagnosed with dementia}

Work is a major component in the lives of many dementia patients. These employees face challenges in sustaining adequate vocational functioning over time and their financial security is constantly under threat (Ritchie et al., 2015). Many experience a loss of confidence

\footnotetext{
${ }^{2}$ Notably, knowledge of dementia is particularly poor among racial and ethnic minority group (Cahill et al., 2015).

${ }^{3}$ These interests may in fact conflict with one another. For example, an employer may strive to terminate the employment while the employee may aspire to continue the employment for the longest duration possible.
} 
and increased anxiety during this period, are treated poorly in their workplace and do not receive the resources to which they are entitled (Chaplin \& Davidson, 2014; Ritchie et al., 2015). Overall, even those capable of continuing some form of employment have limited vocational opportunities and workplaces are ill-prepared to identify and support them (Evans, 2016). This highlights the necessity of establishing specialized support and vocational rehabilitation services that will enable employees to maximize their potential (as advocated by Ritchie et al., 2015). Development of strategic policies and educational programs can assist human resources professionals and other relevant personnel to address these sensitive issues in a humane and ethical manner. More generally, organizations will need to transform their work environment to be more responsive to the psychosocial needs of employees with dementia.

\subsection{Policy monitoring and assessment}

Conducting impact assessments (IAs) of the adopted policy is imperative (Adelle \& Weiland, 2012) and should not neglect unintended consequences. For example, a policy that raises obstacles for elderly employee dismissal may unintentionally discourage employers from hiring older employees or minimize raising wage for those already employed. The IAs should focus on labor market efficiency (i.e., increased productivity and tax revenues and other aspects of economic growth) while factoring in additional import interests (i.e., the social and ethical impact of the policy). Finally, there is insufficient research data regarding the effects of dementia on the workplace (Ritchie et al., 2015). Further research is, therefore, called for in order to inform future policies and assess their efficacy.

\section{Conclusion}

The increased global life expectancy leads to a growth in the proportion of elderly employees in the labor market. Consequently, dementia and its accompanying decline in vocational functioning impact a growing segment of the workforce. Further complicating matters is the fact the dementia may not be recognized as the source of the employee's vocational decline because of: (a) the slow progression of the disease and difficulty in separating the decline in functioning from that occurring naturally with aging. (b) the fact that certain types of dementias are not manifested by easily identifiable changes in cognition (e.g., FTD). (c) impaired awareness of the employee, as well as lack of knowledge and misconceptions of co-workers and supervisors. These factors mandate a re-evaluation of current labor, retirement, and pension saving policies. Establishing policies that will benefit employees, organizations, and society will necessitate the balancing of diverse perspectives and interests. In our opinion, four key policy recommendations are of importance: (a) Establishing policies that encourage the early diagnosis of dementia that considering the challenges and ethical dilemmas that they rise. (b) Establishing psychoeducational programs to increase knowledge regarding dementia, its effects and the needs of employees diagnosed with the disease. (c) Provision of assistance to employees diagnosed with dementia, enabling respectable retirement when their condition worsens. (d) Continued monitoring of current policies and the study of dementia and its effects of the workplace.

The possible impact of dementia on the workplace did not receive adequate professional and scholarly attention up-to-date. This is of clear importance as the workplace already began to undergo massive changes as a result of the global increase in life expectancy. Hopefully, the current paper will encourage the needed deliberations that these intricate issues mandate. 


\section{References}

Adelle, C., \& Weiland, S. (2012). Policy assessment: the state of the art. Impact Assessment and Project Appraisal, 30(1), 25-33.

Adelman, R. D., Tmanova, L. L., Delgado, D., Dion, S., \& Lachs, M. S. (2014). Caregiver Burden A Clinical Review. Jama-Journal of the American Medical Association, 311(10), 1052-1059.

Baruch, Y., Sayce, S., \& Gregoriou, A. (2014). Retirement in a global labour market: a call for abolishing the fixed retirement age. Personnel Review, 43(3), 464-482.

Berisha, V., Wang, S., LaCross, A., \& Liss, J. (2015). Tracking Discourse Complexity Preceding Alzheimer's Disease Diagnosis: A Case Study Comparing the Press Conferences of Presidents Ronald Reagan and George Herbert Walker Bush. Journal of Alzheimers Disease, 45(3), 959-963.

Braw, Y., Omer, E., \& Ravona-Springer, R. (2012). Challenges in the Clinical Assessment of Mild Cognitive Impairment (MCI). JINA - The official Journal of the Israeli Neurological Association, 10, 18-21.

Brazinova, A., Rehorcikova, V., Taylor, M. S., Buckova, V., Majdan, M., Psota, M., ... Holkovic, L. (2015). Epidemiology of traumatic brain injury in Europe: a living systematic review. Journal of Neurotrauma, 33, 1-30.

Brown, P. J., Devanand, D. P., Liu, X., \& Caccappolo, E. (2011). Functional impairment in elderly patients with mild cognitive impairment and mild Alzheimer disease. Archives of General Psychiatry, 68(6), 617-626.

Bugg, J. M., Zook, N. A., DeLosh, E. L., Davalos, D. B., \& Davis, H. P. (2006). Age differences in fluid intelligence: contributions of general slowing and frontal decline. Brain and Cognition, 62(1), 9-16.

Burtless, G. (2013). The impact of population aging and delayed retirement on workforce productivity. Available at SSRN 2275023.

Cahill, S., Pierce, M., Werner, P., Darley, A., \& Bobersky, A. (2015). A Systematic Review of the Public's Knowledge and Understanding of Alzheimer's Disease and Dementia. Alzheimer Disease \& Associated Disorders, 29(3), 255-275.

Castellani, R. J., Rolston, R. K., \& Smith, M. A. (2010). Alzheimer Disease. Dm Disease-aMonth, 56(9), 484-546.

Chaplin, R., \& Davidson, I. (2014). What are the experiences of people with dementia in employment? Dementia, 1471301213519252.

Christensen, K., Doblhammer, G., Rau, R., \& Vaupel, J. W. (2009). Ageing populations: the challenges ahead. Lancet, 374(9696), 1196-1208.

Chuderski, A. (2013). When are fluid intelligence and working memory isomorphic and when are they not? Intelligence, 41(4), 244-262.

Cox, C. B., \& Pardasani, M. (2013). Alzheimer's in the Workplace: A Challenge for Social Work. Journal of gerontological social work, 56(8), 643-656.

Evans, D. (2016). An exploration of the impact of younger-onset dementia on employment. Dementia, O(0), 1-20.

Figueroa, G. (2016). Neuroethics: the pursuit of transforming medical ethics in scientific ethics. Biological Research, 49.

Fujita, S. (2014). On the causes of declines in the labor force participation rate. Research Rap Special Report, Federal Reserve Bank of Philadelphia, 6.

Hardiman, O., Doherty, C. P., Elamin, M., \& Bede, P. (Eds.) (2016). Neurodegenerative Disorders: A Clinical Guide (2 ed.). Cham, CHE: Springer International Publishing. 
Harper, S. (2014). Economic and social implications of aging societies. Science, 346(6209), 587-591.

Hippius, H., \& Neundörfer, G. (2003). The discovery of Alzheimer's disease. Dialogues in Clinical Neuroscience, 5(1), 101-108.

Hipple, S. F. (2016). Labor force participation: what has happened since the peak? Monthly Labor Review.

Hugo, J., \& Ganguli, M. (2014). Dementia and Cognitive Impairment Epidemiology, Diagnosis, and Treatment. Clinics in Geriatric Medicine, 30(3), 421-442.

Jensen, M., Agbata, I. N., Canavan, M., \& McCarthy, G. (2015). Effectiveness of educational interventions for informal caregivers of individuals with dementia residing in the community: systematic review and meta-analysis of randomised controlled trials. International Journal of Geriatric Psychiatry, 30(2), 130-143.

Jones, M., \& Neary, D. (2016). Overview of frontotemporal dementia and the variety of its clinical presentations. In: B. C. Dickerson (Ed.), Hodges' Frontotemporal Dementia (2 ed., pp. 30-43). Cambridge, UK: Cambridge University Press.

Josephsson, S., Backman, L., Borell, L., Nygard, L., \& Bernspang, B. (1995). Effectiveness of an Intervention to Improve Occupational Performance in Dementia. Occupational Therapy Journal of Research, 15(1), 36-49.

Karev, I., \& Doron, I. (2017). The Human Right to Leisure in Old Age: Reinforcement of the Rights of an Aging Population. Journal of Aging \& Social Policy, 29(3), 276-295.

Kiewiet, D. R., \& McCubbins, M. D. (2014). State and Local Government Finance: The New Fiscal Ice Age. Annual Review of Political Science, 17, 17, 105-122.

Laver, K., Dyer, S., Whitehead, C., Clemson, L., \& Crotty, M. (2016). Interventions to delay functional decline in people with dementia: a systematic review of systematic reviews. BMJ Open, 6(4).

Lehrner, J., Kogler, S., Lamm, C., Moser, D., Klug, S., Pusswald, G., ... Auff, E. (2015). Awareness of memory deficits in subjective cognitive decline, mild cognitive impairment, Alzheimer's disease and Parkinson's disease. International Psychogeriatrics, 27(3), 357-366.

Li, Y., Gao, J., Enkavi, A. Z., Zaval, L., Weber, E. U., \& Johnson, E. J. (2015). Sound credit scores and financial decisions despite cognitive aging. Proceedings of the National Academy of Sciences of the United States of America, 112(1), 65-69.

Loretto, W., \& White, P. (2006). Employers' attitudes, practices and policies towards older workers. Human resource management journal, 16(3), 313-330.

Mathers, C. D., Stevens, G. A., Boerma, T., White, R. A., \& Tobias, M. I. (2015). Causes of international increases in older age life expectancy. Lancet, 385(9967), 540-548.

McDaniel, J. L., \& Brenda, G. (1997). Aging Issues in the Workplace: Assisting Workers Who Provide Eldercare. Workplace Health \& Safety, 45(5), 261-269.

McGrattan, E. R., \& Prescott, E. C. (2017). On financing retirement with an aging population. Quantitative Economics, 8(1), 75-115.

Mehta, K. M., \& Yeo, G. W. (2017). Systematic review of dementia prevalence and incidence in United States race/ethnic populations. Alzheimers \& Dementia, 13(1), 72-83.

Murman, D. L. (2015). The Impact of Age on Cognition. Paper presented at the Seminars in Hearing.

Ohman, A., Nygard, L., \& Borell, L. (2001). The vocational situation in cases of memory deficits or younger-onset dementia. Scandinavian Journal of Caring Sciences, 15(1), 34-43.

Onyike, C. U., \& Diehl-Schmid, J. (2013). The epidemiology of frontotemporal dementia. International Review of Psychiatry, 25(2), 130-137. 
Petersen, R. C., Smith, G. E., Waring, S. C., Ivnik, R. J., Tangalos, E. G., \& Kokmen, E. (1999). Mild cognitive impairment: clinical characterization and outcome. Archives of Neurology, 56(3), 303-308.

Phillips, C. (2017). Lifestyle Modulators of Neuroplasticity: How Physical Activity, Mental Engagement, and Diet Promote Cognitive Health during Aging. Neural Plasticity.

Pinner, G., \& Bouman, W. P. (2003). Attitudes of patients with mild dementia and their carers towards disclosure of the diagnosis. International Psychogeriatrics, 15(3), 279-288.

Prince, M., Bryce, R., Albanese, E., Wimo, A., Ribeiro, W., \& Ferri, C. P. (2013). The global prevalence of dementia: A systematic review and metaanalysis. Alzheimers \& Dementia, 9(1), 63-75.

Rajan, K. B., Wilson, R. S., Weuve, J., Barnes, L. L., \& Evans, D. A. (2015). Cognitive impairment 18 years before clinical diagnosis of Alzheimer disease dementia. Neurology, 85(10), 898-904.

Reitz, C., \& Mayeux, R. (2014). Alzheimer disease: Epidemiology, diagnostic criteria, risk factors and biomarkers. Biochemical Pharmacology, 88(4), 640-651.

Ritchie, L., Banks, P., Danson, M., Tolson, D., \& Borrowman, F. (2015). Dementia in the workplace: a review. Journal of Public Mental Health, 14(1), 24-34.

Rossor, M., Collinge, J., Fox, N., Mead, S., Mummery, C., Rohrer, J., ... Warren, J. (2016). Dementia and Cognitive Impairment. In C. Clarke, R. Howard, M. Rossor, \& S. Shorvon (Eds.), Neurology: A Queen Square Textbook (pp. 289-336). Chichester, UK: John Wiley \& Sons.

Rycroft, S. S., \& Giovannetti, T. (2017). Alzheimer's Disease and Other Dementia Disorders. In: N. Chiaravalloti \& Y. Goverover (Eds.), Changes in the Brain. New York, NY: Springer.

Seidler, A., Nienhaus, A., Bernhardt, T., Kauppinen, T., Elo, A. L., \& Frolich, L. (2004). Psychosocial work factors and dementia. Occupational and Environmental Medicine, 61(12), 962-971.

Smith, G., \& Rush, B. K. (2006). Normal Aging and Mild Cognitive Impairment (Ch. 2). In: D. K. Attix \& K. A. Welsh-Bohmer (Eds.), Geriatric Neuropsychology: Assessment and Intervention. New York, NY: The Guilford Press.

Staudinger, U. M., Finkelstein, R., Calvo, E., \& Sivaramakrishnan, K. (2016). A Global View on the Effects of Work on Health in Later Life. Gerontologist, 56, S281-S292.

Strech, D., Mertz, M., Knuppel, H., Neitzke, G., \& Schmidhuber, M. (2013). The full spectrum of ethical issues in dementia care: systematic qualitative review. British Journal of Psychiatry, 202(6), 400-406.

Surr, C. A., Gates, C., Irving, D., Oyebode, J., Smith, S. J., Parveen, S., ... Dennison, A. (2017). Effective Dementia Education and Training for the Health and Social Care Workforce: A Systematic Review of the Literature. Review of Educational Research, 87(5), 9661002.

Truxillo, D. M., Fraccaroli, F., Yaldiz, L. M., \& Zaniboni, S. (2017). Age Discrimination at Work. In: Parry \& J. McCarthy (Eds.), The Palgrave Handbook of Age Diversity and Work. London, UK: Palgrave Macmillan.

Van Dalen, H. P., Henkens, K., \& Schippers, J. (2010). Productivity of older workers: perceptions of employers and employees. Population and Development Review, 36(2), 309-330.

van den Dungen, P., van Kuijk, L., van Marwijk, H., van der Wouden, J., van Charante, E. M., van der Horst, H., \& van Hout, H. (2014). Preferences regarding disclosure of a diagnosis of dementia: a systematic review. International Psychogeriatrics, 26(10), $1603-1618$. 
van der Heide, I., van Rijn, R. M., Robroek, S. J. W., Burdorf, A., \& Proper, K. I. (2013). Is retirement good for your health? A systematic review of longitudinal studies. BMC Public Health, 13.

van der Noordt, M., IJzelenberg, H., Droomers, M., \& Proper, K. I. (2014). Health effects of employment: a systematic review of prospective studies. Occupational and Environmental Medicine, 71(10), 730-736.

Verhaeghen, P. (2013). Cognitive Aging. In R. Reisberg (Ed.), The Oxford Handbook of Cognitive Psychology (pp. 1014-1035). New York, NY: Oxford University Press.

Welsh-Bohmer, K. A., \& Warren, L. H. (2006). Neurodegenerative Dementias (Ch. 3). In: D. K. Attix \& K. A. Welsh-Bohmer (Eds.), Geriatric Neuropsychology: Assessment and Intervention (pp. 56-88). New York, NY: The Guilford Press.

Wyss-Coray, T. (2016). Ageing, neurodegeneration and brain rejuvenation. Nature, 539(7628), 180-186. 
Appendix

Employment and participation rates in the labor market by age, 2000 and 2016

\begin{tabular}{|c|c|c|c|c|c|}
\hline & \multirow{2}{*}{$\begin{array}{l}\text { Age } \\
\text { (years) }\end{array}$} & \multirow{2}{*}{ Group } & \multicolumn{2}{|c|}{ Year } & \multirow{2}{*}{$\begin{array}{l}\text { Change between } \\
2000 \text { and } 2016\end{array}$} \\
\hline & & & 2000 & 2016 & \\
\hline \multirow{9}{*}{$\begin{array}{l}\text { Employment- } \\
\text { population ratios }\end{array}$} & \multirow{3}{*}{$64-15$} & All persons (\%) & 65.4 & 67.0 & 2.4 \\
\hline & & Male (\%) & 76.1 & 74.8 & -1.7 \\
\hline & & Female $(\%)$ & 55.0 & 59.4 & 8.0 \\
\hline & \multirow{3}{*}{$>65$} & All persons (\%) & 8.9 & 14.6 & 64.0 \\
\hline & & Male (\%) & 13.4 & 19.4 & 44.8 \\
\hline & & Female (\%) & 5.7 & 10.0 & 75.4 \\
\hline & \multirow{3}{*}{$>75$} & All persons (\%) & 3.8 & 6.5 & 71.1 \\
\hline & & Male (\%) & 6.5 & 10.2 & 56.9 \\
\hline & & Female $(\%)$ & 2.2 & 4.0 & 81.8 \\
\hline \multirow{9}{*}{$\begin{array}{l}\text { Labor market } \\
\text { participation } \\
\text { rates }\end{array}$} & \multirow{3}{*}{$64-15$} & All persons (\%) & 69.9 & 71.1 & 1.7 \\
\hline & & Male (\%) & 80.8 & 80.0 & -1.0 \\
\hline & & Female $(\%)$ & 59.2 & 63.3 & 6.9 \\
\hline & \multirow{3}{*}{$>65$} & All persons (\%) & 9.1 & 14.5 & 59.3 \\
\hline & & Male (\%) & 13.7 & 19.9 & 45.3 \\
\hline & & Female (\%) & 5.8 & 10.2 & 75.9 \\
\hline & \multirow{3}{*}{$>75$} & All persons (\%) & 3.9 & 6.5 & 66.7 \\
\hline & & Male $(\%)$ & 6.6 & 10.3 & 56.1 \\
\hline & & Female (\%) & 2.2 & 4.0 & 81.8 \\
\hline
\end{tabular}

Source: OECD Database. 